\title{
Review of secondary physical conditions associated with lower-limb amputation and long-term prosthesis use
}

\author{
Robert Gailey, PhD, PT; ${ }^{1-2 *}$ Kerry Allen, DPT; ${ }^{1}$ Julie Castles, DPT; $^{1}$ Jennifer Kucharik, DPT; $^{1}$ \\ Mariah Roeder, DPT ${ }^{\mathbf{1}}$ \\ ${ }^{1}$ Department of Physical Therapy, University of Miami Leonard M. Miller School of Medicine, Coral Gables, FL; \\ ${ }^{2}$ Functional Outcomes Research and Evaluation Center, Miami Department of Veterans Affairs Healthcare System, \\ Miami, FL
}

\begin{abstract}
Musculoskeletal imbalances or pathologies often develop into secondary physical conditions or complications that may affect the mobility and quality of life of people with lowerlimb amputation. Using one or more prostheses causes people with amputation to alter the biomechanics of their movement. For example, people with lower-limb amputation often favor and stress their intact lower limb more during everyday activities. This can lead to degenerative changes such as osteoarthritis of the knee and/or hip joints of the intact limb. Since people with amputation spend less time on their residual limb, osteopenia and subsequent osteoporosis often occur secondary to insufficient loading through the long bones of the lower limb. A proper prosthetic fit increases the probability of equal force distribution across the intact and prosthetic limbs during ambulation, thus decreasing the risk of osteoarthritis. People with limb loss commonly complain of back pain, which is linked to poor prosthetic fit and alignment, postural changes, leg-length discrepancy, amputation level, and general deconditioning. We review the literature on secondary complications among people with lowerlimb loss who are long-term prosthesis wearers.
\end{abstract}

Key words: back pain, fracture, leg-length discrepancy, lowerlimb amputation, osteoarthritis, osteopenia, osteoporosis, prosthetics, rehabilitation, secondary complications.

\section{INTRODUCTION}

Amputations during service in the U.S. Armed Forces are a concern not only for service members who have lost limbs during recent military engagements but also for those who experienced limb loss during prior combat and peacetime services. People who have amputations for traumatic, tumor, and congenital reasons are generally younger than 30 years of age at the time of amputation [1]. The majority of service-connected amputations occur before the third decade of life. For example, 21.7 years was the average age at the time of injury for Vietnam service members with amputation discharged from Valley Forge Military Hospital [2]. Losing a lower limb at such a young age is life-altering in many ways. The use of prosthetic or assistive devices must be incorporated into all daily activities and may influence body image, vocation, and other socialization issues.

In the United States, an average of 133,235 amputationrelated hospital discharges occur each year, with the vast majority (82\%) linked to vascular disease [3]. The annual rate of traumatic amputations has declined from 22 to 16 percent of all amputations, with congenital limb deficiency and tumor-related limb loss each accounting for $<1$ percent [4-5]. Conservatively, an estimated 20 percent of people with amputation in the civilian or veteran population underwent amputation early in life and have had to negotiate

Abbreviations: $\mathrm{BMD}=$ bone mineral density, $\mathrm{GRF}=$ ground reaction force, $\mathrm{SACH}=$ solid-ankle cushioned heel.

*Address all correspondence to Robert Gailey, PhD, PT; Miami Department of Veterans Affairs Healthcare System, Functional Outcomes Research and Evaluation Center, 1201 NW 16th Street, Miami, FL 33125; 305-575-7000, ext 4477; fax: 305-284-6128. Email: rgailey@miami.edu DOI: 10.1682/JRRD.2006.11.0147 
a prosthetic and/or assistive device. As a result, altered gait, reduced activity, and other adaptations additionally stress and strain their entire bodies.

Most people with amputation have an active and satisfying quality of life [6-7]. However, the concern is that having an amputation for a long period of time is associated with secondary physical conditions, including osteoarthritis, osteoporosis, back pain, and other musculoskeletal problems. These conditions are believed to result from increased forces on the intact limb and altered body mechanics that occur secondary to limb loss and/or prosthesis use. This article reviews the literature on the impact of altered gait in people with lower-limb amputation and degenerative conditions that may occur to the lower limbs and spine.

\section{SEARCH STRATEGY}

We performed a systematic electronic search of the literature to identify relevant publications from 1970 to May 2006. MEDLINE, OVID, and EMBASE were searched with the key words "amputation" or "amputee" and "osteoarthritis," "osteopenia," "osteoporosis,” and "back pain"; this search provided 26 articles that were specifically related to the aforementioned topics and determined to be appropriate for the review. Likewise, a search with the RECAL Information Services, a comprehensive bibliographic database specific to prosthetics and orthotics, yielded an additional 18 articles. We read, discussed, and determined that each article in this review warranted inclusion. Because all the studies were retrospective and only a limited number of controlled studies in this clinical research area have been performed, the review of the articles was considered liberal. We eliminated all case studies and expert opinions or consensus studies. Selected "classic" articles were retained for historical perspective. After reviewing the initial journal articles, we performed a secondary search using journal articles and books from the reference lists and bibliographies that identified frequently referenced supportive research or classic articles. The remaining references were resources with which we were already familiar.

\section{PROSTHESES}

A prosthetic device is intended to assist with ambulation and performance of daily life activities. However, wearing a prosthesis that does not fit correctly can lead to complications that adversely affect the gait and activity level of people with amputation [8]. Approximately 68 to 88 percent of people with amputation wear a prosthesis at least 7 hours a day to aid mobility and performance of everyday activities [9-11]. Only a small number of people with amputation do not wear their prosthesis for at least part of the day [12]. The vast majority of people with amputation who use a prosthesis walk with at least one gait deviation as a result of improper prosthetic fit or alignment, lack of proper gait training, development of poor habits, or compensation for a secondary physical limitation. Over time, the altered forces on the skeletal and soft tissues of the intact limb can lead to degenerative conditions [13].

A common gait compensation of people with amputation is moving the intact limb toward midline while slightly increasing the external rotation of the lower limb [14]. This posture, combined with increased stance time on the intact limb, may be used to improve medial/lateral stability. Some authors suggest that increased time on the intact limb is an attempt to protect the soft tissues of the residual limb, which are not suited for weight-bearing immediately after amputation [15]. Regardless of the cause of the gait deviation, people with amputation spend more time on the intact limb than the prosthetic limb during ambulation [16-18]. As a result, the load that people with amputation place on their intact limb is greater than the force that people without amputation exert on their lower limbs during natural cadence walking [18-20]. A comparison of ground reaction forces (GRFs) found that people with unilateral amputation have up to 23 percent force asymmetry depending on the type of prosthesis, while people without amputation have $<10$ percent force asymmetry [18,21-26]. The increased net joint moments and power output on the intact limb result in adaptation mechanisms that affect the ankle, knee, and hip of the intact limb [13]. Long-term exposure to higher repetitive loading forces leads to the degeneration of weight-bearing joints and subsequent joint pain [27-28].

With a "good prosthetic fit," the forces acting across the joints of the contralateral limb of a person with transtibial amputation are not significantly greater than the forces acting across the joints of a person without amputation [29-31]. However, Hurley et al. showed that if good prosthetic fit is not maintained throughout the wearer's lifetime, minor compensations can increase stress on the contralateral limb and possibly predispose the long-term prosthesis wearer to premature degenerative arthritis [29]. 
Hurley et al. also suggested that people with amputation might walk slower than people without amputation in an attempt to reduce the forces placed across the joints of their contralateral limb [29]. Kelly et al. reported that people with transtibial amputation experience discomfort or pain that increases in intensity as the magnitude of change in velocity increases; this increase could be a result of increased loading on the intact limb [32].

Differences between prosthetic feet can also affect the forces directed on the intact limb. Some prosthetic feet with dynamic properties that generate an aft shear impulse on the prosthetic limb tend to reduce the fore shear impulse on the intact limb. This effect reduces the resultant GRFs at the intact side heel during initial contact and increases the flexion moment at the knee during loading response [33]. Conversely, the solid-ankle cushioned heel (SACH) foot, a prosthetic foot without dynamic properties, has been found to produce greater forces on the intact limb and increase knee flexion during early stance [33]. The differences in intact limb forces may be attributed to the rollover shape of the prosthetic foot: in a SACH foot, the shorter keel has rollover characteristics such that a rapid "fall off" onto the flexible, soft rubber forefoot occurs, whereas in a dynamic response foot with a longer foot plate or keel, the rollover characteristics are more stable and therefore provide better balance at the end of stance [33-34].

The increased loading of the intact limb that people with amputation exhibit because of their adaptive gait often causes pain and disease in the joints, which may result in some form of degenerative joint disease or disability. Three of the most common secondary complications due to compensatory and/or altered stresses in people with lower-limb amputation are osteoarthritis, osteopenia/osteoporosis, and back pain.

\section{OSTEOARTHRITIS}

Osteoarthritis is primarily a noninflammatory disorder of movable joints and is characterized by an imbalance between the synthesis and degradation of the articular cartilage, leading to the classic pathological changes of wearing away and destruction of cartilage [35]. An abrasion of articular cartilage occurs coupled with formation of new bone at and around joint surfaces. As a result, the joint functionally deteriorates [36]. The bone in osteoarthritis is stiffer than healthy bone. There- fore, the bone in an osteoarthritic joint is less able to absorb the forces, causing them to be transmitted back to the cartilage [37].

Osteoarthritis has been found to be more prevalent in the contralateral limb than the residual limb of people with amputation [13,38-39]. The prevalence of osteoarthritis is of increasing concern, especially for people who have lived with an amputation for a longer time [38]. If people with amputation do not learn to properly use their prosthesis or bear weight equally between the prosthetic and intact limbs, they may further compromise the integrity of their intact limb. Regardless, people with lowerlimb amputation are at risk for developing osteoarthritis of the knee and/or hip on the amputated and intact sides [38]. Table 1 summarizes the research to date on osteoarthritis in people with traumatic, nonvascular amputation.

\section{Knee}

Hungerford and Cockin were the first authors to describe, with American and British World War II veterans, that people with amputation have a higher incidence of patellofemoral osteoarthritic degeneration on their intact limb than do people without amputation [40]. They found that 22 percent of the veterans without amputation had significant patellofemoral osteoarthritis; this percentage increased to 41 percent among the veterans with transtibial amputation and 63 percent among the veterans with transfemoral amputation. Burke et al. found similar results and attributed gait asymmetry and an increased load on the intact limb to the higher incidence of osteoarthritis in the joints of long-term prosthesis users; 27 percent of the subjects with amputation had grades 1 through 3 osteoarthritis of their intact side knee; none had grade 4 osteoarthritis [39].

As knee pain in the intact limb became more prevalent in the clinic, researchers began to investigate contributing factors. For example, people with amputation use the intact limb to compensate for the amputated limb, resulting in an increased load through the knee joint during gait. Mussman et al. interviewed and examined 47 veterans who were a mean 51 years old, had worn a prosthesis for an average of 24 years, and typically had service-connected amputations [41]. Of these veterans with amputation, 64 percent reported that they depended more on their intact limb during activity. Knee pain in the intact limb was the chief complaint of 55 percent of the total sample. Differences between levels of amputation showed that 46 percent of people with transtibial amputation 
Table 1.

Literature summary: Hip and knee osteoarthritis by amputation level, age, and limb in people with traumatic amputation.

\begin{tabular}{|c|c|c|c|c|c|c|c|}
\hline Study & Level & $n$ & $\begin{array}{c}\text { Mean Age } \\
\text { at }\end{array}$ & $\begin{array}{l}\text { Mean Yr } \\
\text { Since }\end{array}$ & $\begin{array}{c}\text { Mean Age } \\
\text { at }\end{array}$ & \multicolumn{2}{|c|}{ Study Results (\%) } \\
\hline \multirow{5}{*}{$\begin{array}{l}\text { Hungerford } \\
\text { \& Cockin, } \\
1975 \text { [1] }\end{array}$} & & & & & & $\begin{array}{l}\text { Knee OA: Amp Limb, } \\
\text { Radiograph }\end{array}$ & $\begin{array}{l}\text { Knee OA: Nonamp } \\
\text { Limb, Radiograph }\end{array}$ \\
\hline & TTA & 63 & - & - & - & NR & 41 \\
\hline & TFA & 54 & - & - & - & NR & 63 \\
\hline & Total & 117 & NR & NR & NR & - & - \\
\hline & Control & NR & - & - & - & NR & 22 \\
\hline \multirow{5}{*}{$\begin{array}{l}\text { Burke et al., } \\
1978 \text { [2] }\end{array}$} & & & & & & $\begin{array}{l}\text { Knee OA: Amp vs Non- } \\
\text { amp Side, Radiograph }\end{array}$ & $\begin{array}{l}\text { Hip OA: Amp vs Non- } \\
\text { amp Side, Radiograph }\end{array}$ \\
\hline & TTA & 22 & - & - & - & $\mathrm{NR}$ & NR \\
\hline & TFA & 19 & - & - & - & NR & NR \\
\hline & Other & 1 & - & - & - & NR & NR \\
\hline & Total & 42 & 48.4 & 24.6 & 23.8 & 0 vs 17 & 5 vs 12 \\
\hline \multirow{5}{*}{$\begin{array}{l}\text { Mussman et al., } \\
1983 \text { [3] }\end{array}$} & & & & & & $\begin{array}{c}\text { Knee pain: Self-Report, } \\
\text { Symptomatic }\end{array}$ & $\begin{array}{l}\text { Hip pain: Self-Report, } \\
\text { Symptomatic }\end{array}$ \\
\hline & TTA & 28 & - & - & - & 46 & 29 \\
\hline & TFA & 16 & - & - & - & 75 & 19 \\
\hline & Other & 3 & - & - & - & - & - \\
\hline & Total & 56 & 51.1 & 24.4 & 26.0 & 55 & 23 \\
\hline \multirow{3}{*}{$\begin{array}{l}\text { Lemaire \& Fisher, } \\
1994 \text { [4] }\end{array}$} & & & & & & $\begin{array}{c}\text { Knee OA: Amp Side, } \\
\text { Radiograph }\end{array}$ & $\begin{array}{c}\text { Knee OA: Nonamp Side, } \\
\text { Radiograph }\end{array}$ \\
\hline & TTA & 12 & 71.8 & 46.2 & 25.6 & NR & 83 \\
\hline & Control & 12 & 69.8 & - & - & - & 50 \\
\hline \multirow{4}{*}{$\begin{array}{l}\text { Kulkarni et al., } \\
1998 \text { [5] }\end{array}$} & & & & & & $\begin{array}{l}\text { Hip OA: Amp Side, } \\
\text { Radiograph }\end{array}$ & $\begin{array}{l}\text { Hip OA: Nonamp Side, } \\
\text { Radiograph }\end{array}$ \\
\hline & TTA & 29 & - & - & - & 45 & NR \\
\hline & TFA & 15 & - & - & - & 73 & NR \\
\hline & Total & 44 & 73.0 & 47.0 & 26.0 & 55 & 18 \\
\hline \multicolumn{8}{|c|}{$\begin{array}{l}\text { 1. Hungerford DS, Cockin J. Fate of the retained lower limb joints in Second World War amputees. Proceedings and Reports of Universities, Colleges, Councils and } \\
\text { Associations. 1975;57(B1):111. }\end{array}$} \\
\hline \multicolumn{8}{|c|}{ 2. Burke MJ, Roman V, Wright V. Bone and joint changes in lower limb amputees. Ann Rheum Dis. 1978;37(3):252-54. [PMID: 150823] } \\
\hline \multicolumn{8}{|c|}{$\begin{array}{l}\text { 3. Mussman M, Altwerger W, Eisenstein J, Turturro A, Glockenberg A, Bubbers L. Contralateral lower extremity evaluation with a lower limb prosthesis. J Am } \\
\text { Podiatry Assoc. 1983;73(7):344-46. [PMID: 6875169] }\end{array}$} \\
\hline \multicolumn{8}{|c|}{ 4. Lemaire ED, Fisher RF. Osteoarthritis and elderly amputee gait. Arch Phys Med Rehabil. 1994;75(10):1094-99. [PMID: 7944914] } \\
\hline \multicolumn{8}{|c|}{$\begin{array}{l}\text { 5. Kulkarni J, Adams J, Thomas E, Silman A. Association between amputation, arthritis and osteopenia in British male war veterans with major lower limb ampu- } \\
\text { tations. Clin Rehabil. 1998;12(4):348-53. [PMID: 9744670] }\end{array}$} \\
\hline $\begin{array}{l}\text { Amp = amputated, Cc } \\
\text { stibial amputation. }\end{array}$ & trol $=$ non & abled & rol, Nonamp $=$ & nnamputated, NR & = not reported, $\mathrm{O}$ & = osteoarthritis, TFA = transf & noral amputation, TTA = tran- \\
\hline
\end{tabular}

compared with 75 percent of people with transfemoral amputation had knee pain symptoms. Body weight is a concern with osteoarthritis, but Mussman et al. did not report a remarkable difference in knee pain between those subjects who had either gained or lost body weight [41].
Norvell et al. investigated the prevalence of selfreported osteoarthritis symptoms in 63 male veterans with traumatic amputation and controlled for body weight at ages 18 and 30 [42]. The authors hypothesized that if an amputation leads to increased weight gain because of a 
sedentary life style, increased body weight may explain the increased risk of osteoarthritis. While the subjects with amputation had slightly higher body weights than the controls without amputation, the authors determined, after controlling for body weight, that the subjects with transtibial amputation were three times and the subjects with transfemoral amputation five times more likely to have knee pain on the intact side than the controls.

Moreover, Norvell et al. concluded that the stresses that people with amputation place on their intact knee may contribute to the increased risk of knee osteoarthritis. Using the Chronic Pain Grade questionnaire, they found that 16.1 percent of the subjects with transtibial and transfemoral amputations reported symptoms of osteoarthritis compared with 11.7 percent of the subjects without amputation. Moreover, the prevalence of knee pain was 20.3 percent for the subjects without amputation as opposed to 36.4 and 50.0 percent for the subjects with transtibial and transfemoral amputations, respectively [42]. The results indicate that persons with unilateral lower-limb amputation decrease pressure on the amputated side and increase pressure on the intact side, increasing their risk for skeletal deformation in the form of osteoarthritis and resulting in secondary disability.

Hurley and colleagues found that the gait patterns of seven younger subjects with amputation were more asymmetric and slower than nonamputee gait patterns [29]. All subjects were fitted with a dynamic response foot and reported to be satisfied with their prosthesis and, thus, a good prosthetic fit. GRF data from force plates with video gait analysis determined that no statistical difference existed in vertical joint reaction forces across the contralateral limb; therefore, the authors concluded that people with long-term transtibial amputation who have a good prosthetic fit are not predisposed to premature degenerative arthritis [29]. The lack of difference in vertical reaction forces was attributed to lower push off force from the amputated side and slower walking speed $[29,43]$. Lewallen et al. reported similar findings with children with limb loss who exhibited asymmetrical gait patterns without increased forces across the joints of the intact lower limb [31]. Again, slower walking speed, decreased step length, increased double support time, and increased stance time were attributed to the lack of increased moments at the contralateral knee [31,43].

Lemaire and Fisher found a greater prevalence of osteoarthritis in the intact limb of long-term prosthesis users with an average time since amputation of 46 years than in a similar control group without amputation [43]. Their results showed that older people with traumatic transtibial amputation had a higher risk of experiencing larger forces at the knee of their intact limb and of developing osteoarthritis than did those without lower-limb amputation. The group with amputation had a significantly shorter stride length and lower average walking velocity than the control group. Knee joint reaction forces, as measured with force plates, did not significantly differ between the group with amputation and the control group. However, the subjects with osteoarthritis exhibited significantly higher vertical knee joint reaction forces on the intact limb at terminal stance. At weight acceptance, the vertical forces were approximately 12 percent greater and the horizontal forces approximately 19 percent greater for the group with amputation than the control group. Therefore, Lemaire and Fisher suggested that people with transtibial amputation have an increased tendency to develop osteoarthritis in their intact knee. While this increased risk is likely because of multiple factors, the primary mechanism of pathology was attributed to the application of larger-than-normal loads on the affected joint over an extended period [43].

Melzer and colleagues compared osteoarthritis of the intact limb joint among male subjects with amputation who played volleyball $(n=8)$, with amputation who did not play volleyball $(n=24)$, and without amputation who did not play volleyball $(n=24)$ [44]. Three physicians blinded to the subjects' group assignments examined the radiographs. The most common findings among the subjects with amputations were patellar and medial osteophytosis of the tibiofemoral joint, with a tendency of medial narrowing of the tibiofemoral joint space. While the rate of osteoarthritis in all subjects with amputation was 65.6 percent higher than in the control group, the authors did not determine whether participation in competitive sports affected the course of osteoarthritis of the intact knee. They concluded that participation in sport or other high-impact activities should not be discouraged in people with amputation on the basis of risk of degenerative joint disease of the intact limb [44].

To understand why people with amputation are predisposed to premature joint degeneration, Royer and Koenig compared the prosthetic limb with the contralateral limb to investigate frontal plane net joint moments with respect to the mechanics of gait and bone mineral density (BMD) of the proximal tibia of people with unilateral transtibial amputation $(n=9)$ [45]. An age- 
matched control group ( $n=9)$ was enrolled, as well. The proximal tibial, peak knee, internal abduction moment on the intact limb was 56 percent greater than on the prosthetic side knee, whereas in the control group's intact limb knee, it was 24 percent higher than in the prosthetic limb knee [45]. In contrast, when comparing prosthetic feet characteristics, Underwood et al. reported only a 5 percent difference in internal abduction moment at the knee among people with transtibial amputation $(n=11)$ [46]. Royer and Koenig also found that BMD at the proximal tibia was 45 percent larger in the contralateral limb knee than the prosthetic limb knee. They suggested that the contralateral knee experiences greater mechanical loading than the prosthetic limb, as reflected by the increased BMD, which may predispose people with transtibial amputation to premature joint degeneration, particularly knee osteoarthritis $[45,47]$.

\section{Hip}

Increased mechanical stress increases an individual's susceptibility to osteoarthritis of the hip [48]. Not surprisingly, therefore, people with amputation have been found to be at increased risk for osteoarthritis of the hip as a result of the increased load on the intact limb during ambulation. Burke et al. was the first to report radiographic evidence of a slight increase in osteoarthrosis in the intact hip (16.7\%) compared with the amputated side [39].

Mussman et al. reported that 23 percent of veterans with amputation experienced contralateral hip pain [41]. The authors found a higher incidence of hip pain among the veterans with transtibial amputation (29\%) than the veterans with transfemoral amputation (19\%).

Kulkarni et al., examining 44 World War II veterans with service-connected amputation, used radiographs to determine the existence of osteoarthritis based on a minimum joint space threshold of $<2.5 \mathrm{~mm}$ [38]. They hypothesized that increased weight-bearing would lead to increased osteoarthritis in the intact limb. However, 55 percent of the hips on the amputated side and 18 percent on the intact side were positive for osteoarthritis. On the basis of Kellgren and Lawrence grades of $>2 / 5$ [49], the authors found that 61 percent of hips on the amputated side versus 23 percent of hips on the intact side were osteoarthritic. The findings revealed a three- to sixfold increase in osteoarthritis of both the amputated and intact hips compared with age-matched veterans without amputation. A threefold increase of osteoarthritis was found for transfemoral compared with transtibial amputation [38].
Underwood et al. reported a 29 percent greater internal abduction moment for the contralateral limb hip than for the prosthetic side limb in people with transtibial amputation [46]. Royer and colleagues found 33 [45] and 39 [47] percent greater internal abduction moment at the contralateral hip in people with transtibial amputation. A significant positive correlation between peak hip internal abduction moments and femoral neck BMD has been established in subjects without amputation who have hip osteoarthritis [48]. The mechanical loading difference between the hips of people with transtibial amputation $(n=9)$ was also apparent: the femoral neck BMD was 12 percent greater on the intact side, although this result was not statistically significant [45]. The elevated BMD suggests the potential for premature joint degradation; however, Royer and Koenig did not find differences among the intact, prosthetic, and control limbs [45]. The authors suggested that, while the hip internal abduction moments were significantly greater on the prosthetic limb than on the contralateral limb, the femoral neck BMD may be more related to hip flexor and extensor musculature in the sagittal plane, which may function normally and produce near-normal hip joint loading [45]. Comparing the contralateral and prosthetic limbs with the control limbs, the authors found that the internal abduction moment was 23 percent greater and 8 percent smaller, respectively. Regarding $\mathrm{BMD}$, the control and contralateral limbs showed no difference, whereas the prosthetic limb was 10 percent lower at the femoral neck [45]. Although lower BMD was found, osteoporosis was not referenced.

\section{OSTEOPENIA AND OSTEOPOROSIS}

Osteopenia, defined as a state of low bone mass, is characterized by a BMD of 1.0 to 2.5 standard deviation below normal for the individual's sex, age, and race [50], while osteoporosis is defined by a BMD of 2.5 or more standard deviation below normal. Individuals with osteopenia or osteoporosis are more susceptible to bony fractures. In fact, an individual may not know he or she is osteoporotic until a fracture occurs [51]. We subsequently reviewed evidence that suggests that people with amputation are at an increased risk for osteopenia and osteoporosis.

Loss of bone density and the potential for associated risks such as fractures are concerns with aging individuals. Hungerford and Cockin first suggested that 90 percent 
of subjects with transfemoral amputation showed on radiographs the characteristic findings of osteoporosis, including concentric joint space narrowing and absence of osteophytes [40]. Subjects with transtibial amputation also showed marked osteoporosis but, as with those with transfemoral amputation, the description of osteoporosis was not quantified. Likewise, Burke et al. reported that 88 percent of all subjects with amputation studied had osteoporosis in the amputated limb on radiographs [39]. Benichou and Wirotius, in a radiographic survey, reported osteoporosis in all 53 subjects with transfemoral amputation examined, signifying that the majority of people with transfemoral amputation may be at risk for loss of bone density over time [52].

Rush et al. used dual energy X-ray absorptiometry to compare the bone density of the femoral neck of the amputated side with that of the intact femur in 16 male subjects with nondysvascular transfemoral amputation [53]. An average 28 percent loss of BMD was found in 81 percent of the subjects. Rush et al. then reported three important relationships: (1) a significant negative correlation between severity of osteopenia and the subject's age at amputation, (2) a significant negative correlation between severity of osteopenia and the subject's age at examination, and (3) no correlation between residual limb length or duration after amputation and bone density [53]. Compared with controls without amputation, all subjects had normal BMD in their spines and femurs. Most people with unilateral transfemoral amputation have femoral neck osteopenia on the amputated side. Likewise, Kulkarni et al. found that 44 male World War II veterans with amputation had significantly less femoral neck BMD on the amputated side than the intact side. Subjects with transfemoral amputation had significantly lower BMD in the femoral neck of the amputated side than did subjects with transtibial amputation [38]. The implication is that development of osteoporosis is imminent.

The increased incidence of osteopenia for prosthesis wearers creates concern about increased risk of fallrelated fractures. Clinicians might hypothesize that the loss of bone density and the disuse atrophy found in people with amputation contribute to such fractures. Unfortunately, the publications on fractures in this population neither offer data supporting the relationship between BMD and incidence of residual-limb fractures nor agree on risk factors such as age, level of amputation, and time after amputation [54-57].

The literature to date does not conclusively support a direct relationship between low BMD and residual limb fractures among people with lower-limb amputation. The literature that we found on amputation-related fractures is presented in Table 2. Rush et al. in 1994 [53] and Kulkarni et al. in 1998 [38] found that osteopenia was more prevalent among people with amputation because disuse atrophy led to decreased muscle mass, lack of muscular contraction during activity, and immobilization of the residual limb in the socket. Other authors suggest that lack of exercise may be associated with increased bone absorption [58-60]. Also, the decreased vertical loading on the residual limb may cause disuse atrophy and, thus, osteoporosis of the residual femur. The literature reports that people with transfemoral amputation have lower BMD in their residual femurs than do people with transtibial amputation [38].

\section{BACK PAIN}

Back pain is very common in the general population; however, the frequency of back pain is not consistently reported in the literature. An estimated 70 to 85 percent of all people experience back pain at some point during their life, with an annual prevalence between 15 and 45 percent [61-62]. Yearly estimates for disability secondary to low back pain is 3 to 6 percent of the population [63].

Burke et al. was the first to report radiographic findings of the spine in people with lower-limb amputation. They observed scoliosis in 18 of the 42 subjects (43\%). Degenerative changes of varying grades were present in the lumbar spine of 32 subjects (76\%). Prevalence of pain or physical limitations were not discussed [39].

As common as back pain is among the general population, people with amputation seem to be at even greater risk for back pain. In 2000, Ehde et al. found that 52 percent of their subjects with amputation reported persistent, bothersome back pain. Seventeen percent stated that their back pain was the worst pain problem they experienced [64-65]. Back pain commonly occurs in people with lowerlimb amputation and can cause chronic disability. Kulkarni et al. found that 63 percent of subjects with amputation experienced moderate to severe back pain and 60 percent had back pain that commenced within 2 years of the amputation [66]. Among these subjects, 9 percent reported constant back pain and 38 percent said that it interfered significantly with their lifestyle.

Given the relatively high incidence of back pain in Western culture, a portion of the population of people with amputation may be similarly predisposed to back pain and 
JRRD, Volume 45, Number 1, 2008

Table 2.

Summary of postamputation fractures by cause and level of amputation, fracture site, interval between amputation and fracture, and cause of fracture.

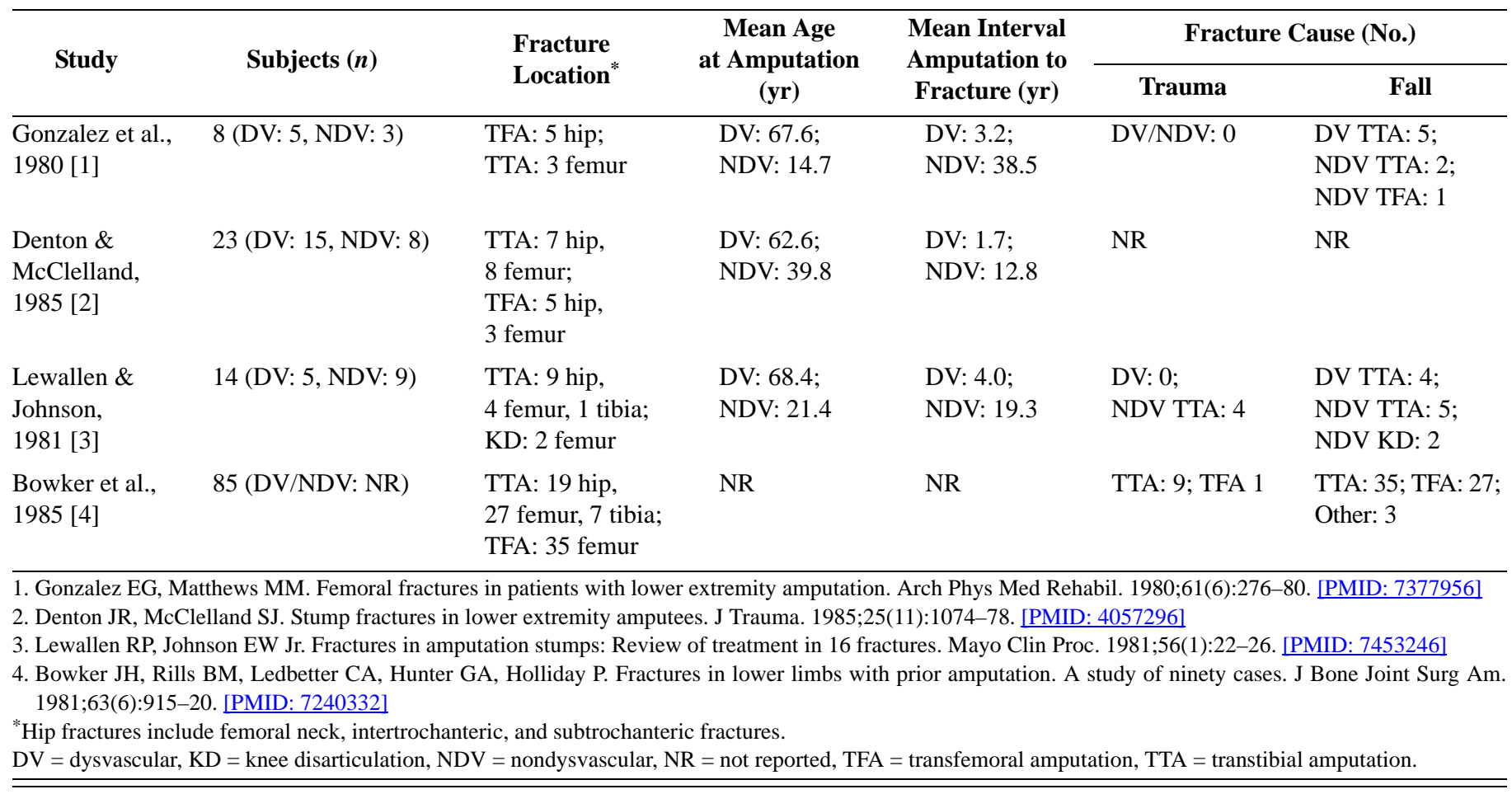

would experience symptoms associated with back pain regardless of limb loss. Persons with nonvascular amputation may, however, be at an increased risk for back pain because of factors not relevant to the general population, such as poor socket fit and prosthetic alignment, abnormal posture, leg-length discrepancy, amputation level, and general deconditioning. Whether these additional factors contribute to the incidence of back pain or exacerbate its expression is unclear. A few investigators have examined some factors that are suggested to contribute to back pain in people with lower-limb amputation.

The majority of people with amputation who use a prosthesis daily but have associated socket instability, discomfort, or residual limb pain adopt a gait strategy that places greater dependence on the intact limb [67]. People with amputations tend to spend more time on their intact limb and walk with the intact limb adducted [1618]. As a result, increased forces act on the joints of the intact limb and decreased forces are applied across the amputated limb during self-selected cadence walking [18-20]. While many authors associate the increased vertical forces on the intact limb with osteoarthritic changes on the intact limb joints and asymmetry of gait, surpris- ingly, aside from clinical supposition, little evidence supports an increased incidence of back pain associated with gait deviations.

\section{Socket Fit and Prosthetic Alignment}

Between 30 and 100 percent of people with lowerlimb amputation report problems that cause discomfort or residual-limb complications that alter their walking ability. Their inability to walk interferes with daily activities and prevents them from wearing their prosthesis, which ultimately reduces quality of life [8,68-69]. Dillingham et al. examined prosthesis satisfaction among 78 people with traumatic amputation [70]. Only 43 percent reported satisfaction with the comfort of their prosthesis and 24 percent reported skin irritation and wounds due to prosthesis use. Sherman, studying a sample of people with traumatic amputation $(n=43)$, found that all subjects had problems associated with their prosthesis and 39 (91\%) had residuallimb pain that interfered with prosthesis use [8]. Conversely, Pezzin et al. reported that although many subjects with amputation complained about their prosthesis, the majority were satisfied enough with its overall performance to use it most of the day [69]. 
While socket fit may be considered the most important parameter in the success of a lower-limb prosthesis, correct alignment also affects walking ability and stress on the contralateral limb [71-72]. Alignment of a prosthesis is the relative position and orientation of the prosthetic components and affects comfort, function, and cosmesis. Improper alignment can contribute to poor socket fit; either would result in undesirable pressure distribution at the residual-limb/socket interface and cause discomfort, pain, and potential tissue breakdown [73]. Currently, the effects of alignment on the gait of people with amputation are not fully understood and acceptable alignment appears to range [71,74]. The flexion and extension of socket alignment and, to a lesser extent, the alignment of the prosthetic foot and ankle components have been found to affect GRFs through joint moments on the prosthetic limb [73]. However, no studies found investigated the relationship between socket or prosthetic alignment and back pain.

\section{Posture and Leg-Length Discrepancy}

During standing, weight-bearing is presumed to be shared equally between the lower limbs. People with transtibial and transfemoral amputation stand with greater sway and more weight bearing toward the intact limb [7577]. The increased sway and dependence on the intact limb have been related to the prosthetic limb's lack of proprioception [11,75,78]. This increased dependence is also present during gait initiation, when people with amputation often bear weight on the intact rather than the residual limb [78]. In fact, people with amputations of all levels have been found to increase stance time on the intact limb and this reliance on the intact limb continues throughout the gait cycle $[16,79]$.

Pelvic tilt is the angle between the horizontal plane and a line passing through the midpoint of the posterior superior iliac spines and the midpoint of the anterior superior iliac spine [80]. Previous literature states that the average range of motion available at the pelvis is $11^{\circ}$ $\left( \pm 4^{\circ}\right)$ [81]. Currently, no normative data indicate the pelvic tilt range of motion in people with amputation. However, a compensatory anterior pelvic tilt of $10^{\circ}$ has been described in people with transfemoral amputation and permits the prosthetic limb to achieve the $15^{\circ}$ of hip extension needed for normal step length [82]. Day et al. showed that a posture of maximum anterior pelvic tilt significantly increases the depth of lumbar lordosis [83]. Furthermore, an increased lumbar lordosis has been associated with an increased likelihood of back pain in people with lower-limb amputation [65].
People with transfemoral amputation can present various gait deviations due to decreased hip extension range of motion of the residual limb. The most likely etiology for decreased hip extension range of motion is iliopsoas tightness [84]. Lack of iliopsoas flexibility can also result in difficulty initiating the swing phase of gait, consequentially promoting hip hiking, increased posterior rotation of the pelvis, or some other gait deviation [85]. Kerrigan et al. state that increased anterior pelvic rotation, shortened step length, or both may occur to compensate for the reduced peak hip extension [86]. Lee et al. discovered that anterior pelvic rotation was more strongly correlated with reduced hip extension during gait than were other compensatory mechanisms [87]. If people with amputation have $<5^{\circ}$ of hip extension available, then compensatory lumbar lordosis and shortened step length on the intact side will result [88].

In the general population, the association between mild leg-length inequality and back pain has been questioned [89]. Several studies suggest that leg-length inequality contributes to back pain [90-93]. Other studies did not find a relationship between leg length and back pain [94-96].

People with amputation who have a prosthesis that is the same length as their intact limb have significantly fewer pain symptoms than those with marked asymmetry between their prosthetic and intact limbs [92,97]. Some of the more common changes observed as a result of a leg-length discrepancy are lateral tilting of the pelvis in the frontal plane, pelvic torsion in the sagittal plane, and lumbar scoliosis [97]. Gofton reports that a $4^{\circ}$ lateral tilt of the sacrum of a compensatory scoliosis in the lumbar spine can be caused by a leg-length discrepancy of only $12.5 \mathrm{~mm}$ [98].

Leg-length discrepancy due to improper prosthetic fit in people with amputation contributes to back pain and other musculoskeletal disorders. Friberg evaluated 113 Finnish subjects with war-related amputation to determine the frequency and consequences of an asymmetrical prosthetic length [97]. The author determined that only 15 percent of the subjects with lower-limb amputation wore a prosthesis equal in length to the intact limb, while 34 percent had an unacceptable leg-length discrepancy of $>20 \mathrm{~mm}$. In 79 percent of the cases of unacceptable leg length, the limb with the prosthesis was shorter than the intact limb. This resulted in back pain symptoms and lateral trunk asymmetry. A prosthetic shortening of 5 and $10 \mathrm{~mm}$ in people with transtibial and transfemoral amputation, respectively, led to problems such as functional scoliosis, 
chronic back pain, and knee or hip pain in the intact limb. For the subjects reporting little to mild back pain, a leglength discrepancy of only $6.1 \mathrm{~mm}$ was found [97].

Young et al. studied the effects of leg-length discrepancy on pelvis position in a group of subjects without amputation and found a lateral pelvic tilt toward the shorter leg when leg-length inequalities were $>15 \mathrm{~mm}$ [99]. Their findings suggest that a major factor contributing to back pain in people with amputation is the postural changes that may occur because of a leg-length discrepancy [99]. Gurney reported that the GRFs of longer limbs are greater than those of shorter limbs [100].

People with transfemoral amputation have back pain that is more bothersome and intense than that experienced by people with transtibial amputation [101]. Likewise, Kulkarni et al. reported that 81 percent of people with transfemoral amputation had back pain compared with 63 percent of those with transtibial amputation [66].

\section{General Deconditioning}

Relatively little evidence addresses the issue of general physical deconditioning and back pain in people with amputation. Kulkarni et al. examined 40 people with traumatic amputation (10 each with transtibial or transfemoral amputation and with or without back pain) who underwent computerized gait analysis, magnetic resonance scanning, and gait/standing stability analysis [66]. They reported that the subjects with transfemoral amputation were more likely to have back pain (81\%) than the subjects with transtibial amputation (63\%). Those subjects with amputation with a body mass index of $>50$ percent were more likely to have back pain. The negative magnetic resonance imaging scan findings, gait asymmetries, and standing stability differences suggest musculoskeletal imbalances as opposed to degenerative arthritis-related pain. [66]. Friel et al. reported on a group of 11 subjects with transtibial and 8 with transfemoral amputation and found that the subjects with transfemoral amputation had stronger back extensors muscles with less muscular endurance than the subjects with transtibial amputation [102]. Moreover, significant differences in back extensor strength, back extensor muscle endurance, and iliopsoas muscle length were found between subjects with amputation who did and did not have back pain [102]. Although future investigations are required, early intervention of gait training and postural therapy have been suggested to benefit people with amputation who have back pain [66].

\section{CLINICAL IMPLICATIONS AND FUTURE RESEARCH}

The new generation of people with limb loss auspiciously appears to have higher expectations concerning their performance of everyday tasks and recreational activities. They want to work, play, and live life without limitations and enjoy the benefits of increased activity, such as better overall health and well-being. However, as activity increases and is sustained over time, concern should be raised about the long-term effects on the musculoskeletal system. For example, will people with amputation who are more active during their youth and early adulthood pay the price later in increased risk of secondary conditions, such as degenerative joint changes to the contralateral limb, remaining joints of the amputated limb, and spine? In our review of the literature, we found that the risk of degenerative joint disease and back pain increases after amputation, with the prevalence greater in people with transfemoral amputation than transtibial amputation. However, we found little evidence to suggest that amount or type of activity increases the risk of secondary conditions after amputation.

Our review of the literature did not find any studies on clinical interventions that prevent or treat secondary conditions associated with amputation. Currently, precautionary measures or clinical interventions for reducing the onset or severity of degenerative joint disease or back pain are based on anecdotal clinical judgment. For example, decreasing the reliance on the nonamputated limb during walking, standing, or performing everyday activities would theoretically reduce stresses on the joints of the lower limb and reduce compensatory movement strategies that alter the mechanics of the spine. Convention suggests that a comprehensive program that includes quality prosthetic care and proper physical conditioning would be beneficial.

Submitting an exhaustive list of research possibilities is beyond the scope of this literature review; however, some areas for future research on secondary conditions related to lower-limb amputation would include the following topics. Research is needed to understand the incidence of degenerative joint disease and how it affects the joints of the lower limbs and spine. While current studies demonstrate that secondary conditions are present after amputation, validation of predictive profiles is needed to predetermine which individuals with amputation are at greatest risk. Studies are needed to define good prosthetic fit and determine 
the implications of poor prosthetic fit. Likewise, studies are needed to determine the differences between socket designs and prosthetic components with respect to forces placed on the contralateral limb and spine. Similarly, studies that investigate prosthetic socket alignment and prosthetic length and the relationship to the hip, pelvis, and spine in people with transfemoral amputation may have significant clinical value. In addition, the effects of traditional therapies, such as orthotic shoe inserts for medial knee pain, or pharmacological and nonpharmacological therapies for osteoarthritis and osteoporosis should be explored. Studies investigating therapeutic interventions such as balance training, strengthening, gait training, and other movement strategies should be investigated with respect to load sharing with the prosthetic limb and to stress reduction on the contralateral limb. Finally, research exploring the effects of physical conditioning, especially to stabilize the trunk muscles to reduce back pain and maintain an active lifestyle, may guide clinicians and prosthesis users alike.

\section{CONCLUSIONS}

Musculoskeletal pathologies often develop as secondary complications in people with amputation, which may affect their mobility and quality of life. An alteration of biomechanics occurs with the use of one or more prostheses. Individuals with amputation tend to favor their intact limb and stress it more during mobility and daily activities. This tendency can cause degenerative changes of the intact limb, such as osteoarthritis of the knee and/ or hip joints. Since people with amputation spend less time on their residual limb, osteopenia and subsequent osteoporosis often occur secondary to insufficient loading of the bones. Prosthetic fit and alignment can influence posture and comfort, which may promote greater equal force distribution across the intact and prosthetic sides during gait and tentatively decrease the susceptibility to osteoarthritis. Moreover, back pain that is bothersome and influences activity is a common complaint among individuals with amputation. Back pain has been linked to poor socket fit and alignment, postural changes, leg-length discrepancy, amputation level, and general deconditioning. Knowledge of the possible secondary complications of amputation can help rehabilitation practitioners provide high-quality, prophylactic care for their patients with lower-limb amputation.

\section{ACKNOWLEDGMENTS}

This material was unfunded at the time of manuscript preparation.

The authors have declared that no competing interests exist.

\section{REFERENCES}

1. Stern PH. The epidemiology of amputations. Phys Med Rehabil Clin North Am. 1991;2(2):253-61.

2. Dougherty PJ. Transtibial amputees from the Vietnam War. Twenty-eight-year follow-up. J Bone Joint Surg Am. 2001; 83-A(3):383-89. [PMID: 11263642]

3. Adams PF, Hendershot GE, Marano MA, Centers for Disease Control and Prevention/National Center for Health Statistics. Current estimates from the National Health Interview Survey, 1996. Vital Health Stat 10. 1999;(200): 1-203. [PMID: 15782448]

4. Glattly HW. A statistical study of 12,000 new amputees. South Med J. 1964;57:1373-78. [PMID: 14195964]

5. McCaig L, Ly N, National Hospital Ambulatory Medical Care Survey: 2000 emergency department summary. Advanced data from vital and health statistics No. 326 [monograph on the Internet]. Hyattsville (MD): National Center for Health Statistics; 2002 [cited 2007 Dec 7]. Available from: http://www.cdc.gov/nchs/data/ad/ad326.pdf

6. Brodzka WK, Thornhill HL, Zarapkar SE, Malloy JA, Weiss L. Long-term function of persons with atherosclerotic bilateral below-knee amputation living in the inner city. Arch Phys Med Rehabil. 1990;71(11):895-900. [PMID: 2222158]

7. Medhat A, Huber PM, Medhat MA. Factors that influence the level of activities in persons with lower extremity amputation. Rehabil Nurs. 1990;15(1):13-18. [PMID: 2300691]

8. Sherman RA. Utilization of prostheses among US veterans with traumatic amputation: A pilot survey. J Rehabil Res Dev. 1999;36(2):100-108. [PMID: 10661526]

9. Pohjolainen T, Alaranta H, Kärkkäinen M. Prosthetic use and functional and social outcome following major lower limb amputation. Prosthet Orthot Int. 1990;14(2):75-79. [PMID: 2235304]

10. Walker CR, Ingram RR, Hullin MG, McCreath SW. Lower limb amputation following injury: A survey of long-term functional outcome. Injury. 1994;25(6):387-92. [PMID: 8045644]

11. Jones ME, Steel JR, Bashford GM, Davidson IR. Static versus dynamic prosthetic weight bearing in elderly transtibial amputees. Prosthet Orthot Int. 1997;21(2):100-106. [PMID: 9285953] 
12. Burger H, Marincek C, Isakov E. Mobility of persons after traumatic lower limb amputation. Disabil Rehabil. 1997;19(7):272-77. [PMID: 9246543]

13. Nolan L, Wit A, Dudzinski K, Lees A, Lake M, Wychowanksi $\mathrm{M}$. Adjustments in gait symmetry with walking speed in trans-femoral and trans-tibial amputees. Gait Posture. 2003;17(2):142-51. [PMID: 12633775]

14. Engsberg JR, Herbert LM, Grimston SK, Fung TS, Harder JA. Relation among indices of effort and oxygen uptake in below-knee amputee and able-bodied children. Arch Phys Med Rehabil. 1994;75(12):1335-41. [PMID: 7993173]

15. Silver-Thorn MB, Steege JW, Childress DS. A review of prosthetic interface stress investigations. J Rehabil Res Dev. 1996;33(3):253-66. [PMID: 8823673]

16. Breakey J. Gait of unilateral trans-tibial amputees. Orthot Prosthet. 1976;30:17-24.

17. Murray MP, Mollinger LA, Sepic SB, Gardner GM, Linder MT. Gait patterns in above-knee amputee patients: Hydraulic swing control vs constant-friction knee components. Arch Phys Med Rehabil. 1983;64(8):339-45. [PMID: 6882172]

18. Engsberg JR, Lee AG, Tedford KG, Harder JA. Normative ground reaction force data for able-bodied and belowknee amputee children during walking. J Pediatr Orthop. 1993;13(2):169-73. [PMID: 8459005]

19. Suzuki K. Force plate study on the artificial limb gait. J Jpn Orthop Assoc. 1972;46:503-16.

20. Engsberg JR, Lee AG, Patterson JL, Harder JA. External loading comparisons between able-bodied and belowknee amputee children during walking. Arch Phys Med Rehabil. 1991;72(9):657-61. [PMID: 1859261]

21. Hamil J, Bates BT, Knutzen KM, Sawhill JA. Variations in ground reaction force parameters at different running speeds. Hum Mov Sci. 1983;2:47-56.

22. Herzog W, Nigg BM, Read LJ, Olsson E. Asymmetries in ground reaction force patterns in normal human gait. Med Sci Sports Exerc. 1989;21(1):110-14. [PMID: 2927295$]$

23. Zernicke RF, Hoy MG, Whiting WC. Ground reaction forces and center of pressure patterns in the gait of children with amputation: Preliminary report. Arch Phys Med Rehabil. 1985;66(11):736-41. [PMID: 4062525]

24. Menard MR, McBride ME, Sanderson DJ, Murray D. Comparative biomechanical analysis of energy-storing prosthetic feet. Arch Phys Med Rehabil. 1992;73(5):451-58. [PMID: 1580773]

25. Schneider K, Hart T, Zernicke RF, Setoguchi Y, Oppenheim W. Dynamics of below-knee amputee child gait: SACH foot versus Flex foot. J Biomech. 1993;26(10): 1191-1204. [PMID: 8253824$]$

26. Powers CM, Torburn L, Perry J, Ayyappa E. Influence of prosthetic foot design on sound limb loading in adults with unilateral below-knee amputations. Arch Phys Med Rehabil. 1994;75(7):825-29. [PMID: 8024435]

27. Radin EL, Parker HG, Pugh JW, Steinberg RS, Paul IL, Rose RM. Response of joints to impact loading. 3. Relationship between trabecular microfractures and cartilage degeneration. J Biomech. 1973;6(1):51-57. [PMID: 4693868$]$

28. Hurwitz DE, Sumner DR, Block JA. Bone density, dynamic joint loading and joint degeneration. A review. Cells Tissues Organs. 2001;169(3):201-9. [PMID: 11455115]

29. Hurley GR, McKenney R, Robinson M, Zadravec M, Pierrynowski MR. The role of the contralateral limb in belowknee amputee gait. Prosthet Orthot Int. 1990;14(1):33-42. [PMID: 2192355]

30. Eberhart HD, Elfman H, Inman VT. The locomotor mechanism of the amputee. In: Klopsteg PB, Wilson PD, editors. Human limbs and their substitutes: Presenting results of engineering and medical studies of the human extremities and application of the data to the design and fitting of artificial limbs and to the care and training of amputees. New York (NY): McGraw-Hill; 1954.

31. Lewallen R, Quanbury AO, Ross K, Letts R. A biomechanical study of normal and amputee gait. Champaign (IL): Human Kinetics Publishers; 1985.

32. Kelly KM, Doyle W, Skinner HB. The relationship between gait parameters and pain in persons with transtibial amputation: A preliminary report. J Rehabil Res Dev. 1998; 35(2):231-37. [PMID: 9651896]

33. Lehmann JF, Price R, Boswell-Bessette S, Dralle A, Questad K, deLateur BJ. Comprehensive analysis of energy storing prosthetic feet: Flex Foot and Seattle Foot versus standard SACH foot. Arch Phys Med Rehabil. 1993; 74(11):1225-31. [PMID: 8239969]

34. Hansen AH, Childress DS, Knox EH. Prosthetic foot rollover shapes with implications for alignment of trans-tibial prostheses. Prosthet Orthot Int. 2000;24(3):205-15. [PMID: 11195355]

35. Dequeker J, Aerssens J, Luyten FP. Osteoarthritis and osteoporosis: Clinical and research evidence of inverse relationship. Aging Clin Exp Res. 2003;15(5):426-39. [PMID: 14703009]

36. Kraus VB. Pathogenesis and treatment of osteoarthritis. Med Clin North Am. 1997;81(1):85-112. [PMID: 9012756]

37. Dequeker J. The relationship between osteoporosis and osteoarthritis. Clin Rheum Dis. 1985;11(2):271-96. [PMID: 3899487]

38. Kulkarni J, Adams J, Thomas E, Silman A. Association between amputation, arthritis and osteopenia in British male war veterans with major lower limb amputations. Clin Rehabil. 1998;12(4):348-53. [PMID: 9744670]

39. Burke MJ, Roman V, Wright V. Bone and joint changes in lower limb amputees. Ann Rheum Dis. 1978;37(3): 252-54. [PMID: 150823] 
40. Hungerford DS, Cockin J. Fate of the retained lower limb joints in Second World War amputees. Proceedings and Reports of Universities, Colleges, Councils, and Associations. J Bone Joint Surg. 1975;57(B1):111.

41. Mussman M, Altwerger W, Eisenstein J, Turturro A, Glockenberg A, Bubbers L. Contralateral lower extremity evaluation with a lower limb prosthesis. J Am Podiatry Assoc. 1983;73(7):344-46. [PMID: 6875169]

42. Norvell DC, Czerniecki JM, Reiber GE, Maynard C, Pecoraro JA, Weiss NS. The prevalence of knee pain and symptomatic knee osteoarthritis among veteran traumatic amputees and nonamputees. Arch Phys Med Rehabil. 2005; 86(3):487-93. [PMID: 15759233]

43. Lemaire ED, Fisher RF. Osteoarthritis and elderly amputee gait. Arch Phys Med Rehabil. 1994;75(10):1094-99. [PMID: 7944914$]$

44. Melzer I, Yekutiel M, Sukenik S. Comparative study of osteoarthritis of the contralateral knee joint of male amputees who do and do not play volleyball. J Rheumatol. 2001; 28(1):169-72. [PMID: 11196520]

45. Royer T, Koenig M. Joint loading and bone mineral density in persons with unilateral, trans-tibial amputation. Clin Biomech (Bristol, Avon). 2005;20(10):1119-25. [PMID: 16139403]

46. Underwood HA, Tokuno CD, Eng JJ. A comparison of two prosthetic feet on the multi-joint and multi-plane kinetic gait compensations in individuals with unilateral trans-tibial amputation. Clin Biomech (Bristol, Avon). 2004;19(6): 609-16. [PMID: 15234485]

47. Royer TD, Wasilewski CA. Hip and knee frontal plane moments in persons with unilateral, trans-tibial amputation. Gait Posture. 2006;23(3):303-6. [PMID: 15919207]

48. Hurwitz DE, Foucher KC, Sumner DR, Andriacchi TP, Rosenberg AG, Galante JO. Hip motion and moments during gait relate directly to proximal femoral bone mineral density in patients with hip osteoarthritis. J Biomech. 1998;31(10):919-25. [PMID: 9840757]

49. Kellgren JH, Lawrence JS. Radiological assessment of osteo-arthrosis. Ann Rheum Dis. 1957;16(4):494-502. [PMID: 13498604]

50. Kanis JA, Johnell O, Oden A, Jonsson B, De Laet C, Dawson A. Risk of hip fracture according to the World Health Organization criteria for osteopenia and osteoporosis. Bone. 2000;27(5):585-90. [PMID: 11062343]

51. Turner PA. Osteoporosis-Its causes and prevention: An update. Physiother Theory Pract. 2000;16(3):135-49.

52. Benichou C, Wirotius JM. Articular cartilage atrophy in lower limb amputees. Arthritis Rheum. 1982;25(1):80-82. [PMID: 7066039]

53. Rush PJ, Wong JS, Kirsh J, Devlin M. Osteopenia in patients with above knee amputation. Arch Phys Med Rehabil. 1994;75(1):112-15. [PMID: 8291952]
54. Denton JR, McClelland SJ. Stump fractures in lower extremity amputees. J Trauma. 1985;25(11):1074-78. [PMID: 4057296]

55. Lewallen RP, Johnson EW Jr. Fractures in amputation stumps: Review of treatment in 16 fractures. Mayo Clin Proc. 1981;56(1):22-26. [PMID: 7453246$]$

56. Gonzalez EG, Matthews MM. Femoral fractures in patients with lower extremity amputation. Arch Phys Med Rehabil. 1980;61(6):276-80. [PMID: 7377956]

57. Bowker JH, Rills BM, Ledbetter CA, Hunter GA, Holliday P. Fractures in lower limbs with prior amputation. A study of ninety cases. J Bone Joint Surg Am. 1981;63(6): 915-20. [PMID: 7240332]

58. Tanaka T, Latorre MR, Jaime PC, Florindo AA, Pippa MG, Zerbini CA. Risk factors for proximal femur osteoporosis in men aged 50 years or older. Osteoporos Int. 2001;12(11): 942-49. [PMID: 11804021]

59. Smeltzer SC, Zimmerman V, Capriotti T. Osteoporosis risk and low bone mineral density in women with physical disabilities. Arch Phys Med Rehabil. 2005;86(3):582-86. [PMID: 15759248]

60. Koutulainen S, Heinonen A, Kannus P, Pasanen M, Sievanen H, Vuori I. Former exercisers of an 18-month intervention display residual aBMD benefits compared with control women 3.5 years post-intervention: A follow-up of a randomized controlled high-impact trial. Osteoporos Int. 2004;15(3):248-51. [PMID: 14673517]

61. Andersson GB. Epidemiological features of chronic lowback pain. Lancet. 1999;354(9178):581-85.

[PMID: 10470716]

62. Biering-Sorenson F. Low back trouble in a general population of 30-, 40-, 50-, and 60-year old men and women. Study design, representativeness, and basic results. Dan Med Bull. 1982;29(6):289-99. [PMID: 6216075]

63. Frymoyer JW. Back pain and sciatica. N Eng J Med. 1988;318(5):291-300. [PMID: 2961994]

64. Ehde DM, Czerniecki JM, Smith DG, Campbell KM, Edwards WT, Jensen MP, Robinson LR. Chronic phantom sensations, phantom pain, residual limb pain, and other regional pain after lower limb amputation. Arch Phys Med Rehabil. 2000;81(8):1039-44. [PMID: 10943752]

65. Ehde DM, Smith DG, Czerniecki JM, Campbell KM, Malchow DM, Robinson LR. Back pain as a secondary disability in persons with lower limb amputations. Arch Phys Med Rehabil. 2001;82(6):731-34. [PMID: 11387575]

66. Kulkarni J, Gaine WJ, Buckley JG, Rankine JJ, Adams J. Chronic low back pain in traumatic lower limb amputees. Clin Rehabil. 2005;19(1):81-86. [PMID: 15704512]

67. Hill SW, Patla AE, Ishac MG, Adkin AL, Supan TJ, Barth DG. Altered kinetic strategy for the control of swing limb elevation over obstacles in unilateral below-knee amputee gait. J Biomech. 1999;32(5):545-49. [PMID: 10327009] 
68. Chan KM, Tan ES. Use of lower prosthesis among elderly amputees. Ann Acad Med Singapore. 1990;19(6):811-16. [PMID: 2130743]

69. Pezzin LE, Dillingham TR, MacKenzie EJ, Ephraim P, Rossbach P. Use and satisfaction with prosthetic limb devices and related services. Arch Phys Med Rehabil. 2004;85(5):723-29. [PMID: 15129395]

70. Dillingham TR, Pezzin LE, MacKenzie EJ, Burgess AR. Use and satisfaction with prosthetic devices among persons with trauma-related amputations: A long-term outcome study. Am J Phys Med Rehabil. 2001;80(8):563-71. [PMID: 11475475]

71. Zahedi MS, Spence WD, Solomanidis SE, Paul JP. Alignment of lower-limb prostheses. J Rehabil Res Dev. 1986; 23(2):2-19. [PMID: 3723422]

72. Sin SW, Chow DH, Cheng JC. Significance of non-level walking on transtibial prosthesis fitting with particular reference to the effects of anterior-posterior alignment. J Rehabil Res Dev. 2001;38(1):1-6. [PMID: 11322461]

73. Yang L, Solomonidis SE, Spence WD, Paul JP. The influence of limb alignment on the gait of above-knee amputees. J Biomech. 1991;24(11):981-97. [PMID: 1761584]

74. Zahedi MS, Spence WD, Solomonidis SE, Paul JP. Repeatability of kinetic and kinematic measurements in gait studies of the lower limb amputee. Prosthet Orthot Int. 1987;11(2):55-64. [PMID: 3658649]

75. Isakov E, Mizrahi J, Ring H, Suzak Z, Hakim N. Standing sway and weight-bearing distribution in people with below-knee amputations. Arch Phys Med Rehabil. 1992; 73(2):174-78. [PMID: 1543414]

76. Nadollek H, Brauer S, Isles R. Outcomes after trans-tibial amputation: The relationship between quiet stance ability, strength of hip abductor muscles and gait. Physiother Res Int. 2002;7(4):203-14. [PMID: 12528576]

77. Fernie GR, Holliday PJ. Postural sway in amputees and normal subjects. J Bone Joint Surg Am. 1978;60(7):895-98. [PMID: 701337]

78. Rossi SA, Doyle W, Skinner HB. Gait initiation of persons with below-knee amputation: The characterization and comparison of force profiles. J Rehabil Res Dev. 1995; 32(2):120-27. [PMID: 7562651]

79. Winter DA, Sienko SE. Biomechanics of below-knee amputee gait. J Biomech. 1988;21(5):361-67. [PMID: 3417688]

80. Norkin CC, Levangie P. Joint structure and function: A comprehensive analysis. 2nd ed. Philadelphia (PA): F. A. Davis Company; 1992. p. 313-14.

81. Magee DJ. Orthopedic physical assessment. 4th ed. Philadelphia (PA): Saunders; 2002. p. 572-73.

82. Hampton FL. Prosthetic principles in the lower extremity amputee. Orthop Clin North Am. 1972;3(2):339-47. [PMID: 5037520]
83. Day JW, Smidt GL, Lehmann T. Effect of pelvic tilt on standing posture. Phys Ther. 1984;64(4):510-16. [PMID: 6231648]

84. Bogduk NM, Pearcy MJ, Hadfield G. Anatomy and biomechanics of psoas major. Clin Biomech. 1992;7:109-19.

85. Dannenberg HJ. Lower back pain as a gait-related repetitive motion injury. In: Vleeming A, editor. Movement, stability, and low back pain: The essential role of the pelvis. New York (NY): Churchill Livingstone; 1997. p. 253-67.

86. Kerrigan DC, Todd MK, Della Croce U, Lipsitz LA, Collins JJ. Biomechanical gait alterations independent of speed in the healthy elderly: Evidence for specific limiting impairments. Arch Phys Med Rehabil. 1998;79(3): 317-22. [PMID: 9523785]

87. Lee LW, Kerrigan DD, Della Croce U. Dynamic implications of hip flexion contractures. Am J Phys Med Rehabil. 1997;76(6):502-8. [PMID: 9431270]

88. Sanders GT, May BJ. Lower limb amputations: A guide to rehabilitation. 1st ed. Philadelphia (PA): F. A. Davis Company; 1986. p. 242-43.

89. Soukka A, Alaranta H, Tallroth K, Heliovaara M. Leglength inequality in people of working age. The association between mild inequality and low-back pain is questionable. Spine. 1991;16(4):429-31. [PMID: 1828627]

90. Biering-Sorensen F. Physical measurements as risk indicators for low-back trouble over a one-year period. Spine. 1984;9(2):106-19. [PMID: 6233709]

91. Friberg O. Clinical symptoms and biomechanics of lumbar spine and hip joint in leg length inequality. Spine. 1983;8(6):643-51. [PMID: 6228021]

92. Giles LG, Taylor JR. Low-back pain associated with leg length inequality. Spine. 1981;6(5):510-21. [PMID: 6458101]

93. Mahar RK, Kirby RL, MacLeod DA. Stimulated leglength discrepancy: Its effect on mean center-of-pressure position and postural sway. Arch Phys Med Rehabil. 1985;66(12):822-24. [PMID: 4074116]

94. Froh R, Yong-Hing K, Cassidy JD, Houston CS. The relationship between leg length discrepancy and lumbar facet orientation. Spine. 1988;13(3):325-27. [PMID: 3388118]

95. Grundy PF, Roberts CJ. Does unequal leg length cause back pain? A case-control study. Lancet. 1984;2(8397): 256-58. [PMID: 6146810]

96. Pope MH, Bevins T, Wilder DG, Frymoyer JW. The relationship between anthropometric, postural, muscular, and mobility characteristics of males aged 18-55. Spine. 1985; 10(7):644-48. [PMID: 4071274]

97. Friberg O. Biomechanical significance of the correct length of lower limb prostheses: A clinical and radiological study. Prosthet Orthot Int. 1984;8(3):124-29. [PMID: 6240634] 
98. Gofton JP. Persistent low back pain and leg length disparity. J Rheumatol. 1985;12(4):747-50. [PMID: 2932553]

99. Young RS, Andrew PD, Cummings GS. Effect of simulating leg length inequality on pelvic torsion and trunk mobility. Gait Posture. 2000;11(3):217-23. [PMID: 10802434]

100. Gurney B. Leg length discrepancy. Gait Posture. 2002; 15(2):195-206. [PMID: 11869914$]$

101. Smith DG, Ehde DM, Legro MW, Reiber GE, Del Aguila M, Boone DA. Phantom limb, residual limb, and back pain after lower extremity amputations. Clin Orthop Relat Res. 1999;(361):29-38. [PMID: 10212593]

102. Friel K, Domholdt E, Smith DG. Physical and functional measures related to low back pain in individuals with lowerlimb amputation: An exploratory pilot study. J Rehabil Res Dev. 2005;42(2):155-66. [PMID: 15944880]

Submitted for publication November 22, 2006. Accepted in revised form June 25, 2007. 